\title{
Post-secondary apprenticeships for youth: Follow-up case studies
}

\author{
Philip G. Wilson*, Susan G. Killam, Lauren Griffiths, Laura C. Stazio, Rebecca B. Ellis, \\ McKenzie Esta and Amarachi N. Ukachu \\ Human Development Center, LSU Health Science Center, New Orleans, LA, USA
}

\begin{abstract}
.
OBJECTIVE: This paper uses follow-up case studies of two youths who completed the Post-Secondary Apprenticeship for Youth with disabilities (PAY Check) program to chronicle outcomes and lessons learned.

CONCLUSION: The article concludes with recommendations for improving transition programs designed to promote full participation of youth with disabilities in the community as adults.
\end{abstract}

Keywords: Apprenticeships, post-secondary, transition

\section{Introduction}

The late teen years through early 20 s is a critical time to prepare for life after high school and full participation in the community, including future employment and the array of knowledge and skills required for successful independent living in the 21st century. Today's youth must have knowledge and skills in a variety of settings and activities that previous generations did not need to master to successfully transition from high school to what was then considered full participation in the community as adults. In addition to self-care, domestic, and social skills; today's young adults need to be competent and relatively independent using smart phones and tablets, possess financial and health literacy, and be capable of managing their personal transportation, among other things. Twenty years ago, learning to fry an egg, doing laundry and engaging in socially appropriate conversations could be learned and practiced in traditional high school settings. However, if a youth leaves high

*Address for correspondence: Philip G. Wilson, LSUHSCHuman Development Center, 411 So. Prieur Street -4 th Floor Room 472, New Orleans, LA 70112-2262, USA. Tel.: +1 504556 7573; E-mail: pwilso2@1suhsc.edu. school in 2018 without being exposed and supported to engage in skills and using technology required to participate fully in the community in authentic settings and activities of community life she or he will almost certainly remain reliant on others as adults and fail to participate fully in the community.

Recent legislation and public policy that guides the transition process and delivery of supports and services for youth with disabilities (e.g., Workforce Innovation Opportunities Act (WIOA), revisions to the Higher Education Act, Medicaid Setting Rule) appears to acknowledge and encourage professionals charged with planning and implementing programs, supports and services to target 21 st century knowledge, skills, and settings for instruction and practice. For example, WIOA reinforces the previously established intentions of the Individuals with Disabilities Education Act (2015) that requires public schools and state VR to collaborate to ensure that youth with disabilities learn pre-employment transition skills including. Revisions to the Higher Education Act have spurred increased focus on providing access to post-secondary education (PSE) for youth with disabilities and the Medicaid Setting Rule makes clear Congress's intention to promote community participation people with disabilities. 
Collectively, the aforementioned legislative and policy initiatives provide the rationale and mandate to reconceptualize not only the content, but the format and settings in which instruction, supports and services are provided to youth in transition. Professionals charged with planning and supporting youth with disabilities successfully transition to full participation in the community as adults must create access and opportunities for these youth to experience, acquire and practice using the knowledge and skills required to function independently in the community in authentic community settings and activities while they are still receiving instruction, supports and services. This requires simultaneous and coordinated involvement of multiple education and rehabilitation providers (i.e., public schools, state VR, PSE, employers) as well as families and the youth themselves.

This paper uses follow-up case studies of two youths who completed the Post-Secondary Apprenticeship for Youth with disabilities (PAY Check) program to describe outcomes and lessons learned from implementing the program with the first cohort of participants. The article concludes with recommendations for improving the transition programs and outcomes for youth with disabilities to further enhance their full participation in the community as adults.

The PAY Check program is an innovative partnership between the state's University Center of Excellence in Developmental Disabilities, state VR, Local Education Agencies, Delgado Community College (DCC) and University Medical Center-New Orleans. This partnership utilized a collaborative funding approach that braided funding for services and supports. PAY Check includes a high school diploma option, PSE, paid apprenticeship, as well as job placement components. The curriculum includes self-advocacy, independent living and social skills instruction, as well as job and work readiness training. The curriculum incorporates self-determination training throughout. The program serves students ages 18-21 years who are eligible for VR services and receive special education services or have a 504 plan. All components of PAY Check take place in integrated community settings (e.g., DCC campus, public transportation, paid apprenticeship sites) and provide opportunities for participants to acquire and engage in Pre-Employment Transition Skills (Pre-ETS) training delineated in WIOA.

The next section provides a description of two PAY Check completers, Wyatt and Gwen.

\subsection{Wyatt}

Wyatt is a 20-year old young man with two exceptionalities listed on his IEP: mild mental disability and orthopedic health impairment. The majority of his school day while in high school was spent in selfcontained classroom settings. He was placed into a "certificate of completion" graduation path.

When Wyatt was accepted into the PAY Check Program he had the appearance of a confident person. However, it turned out that appearance was masking a lot of underlying insecurities and anxiety. In his early days in the program he would frequently ask each staff person the same question sometimes multiple times to ensure that he knew the correct answer. He also did not set any long term goals for his future.

While in the program, Wyatt truly dug in and gave it his all each day. The PAY Check curriculum includes a focus on teaching and reinforcing selfdetermination skills. Wyatt set goals and met with staff each day to make a plan to achieve his goal(s). He became more proficient on the bus and learned to use the internet on his phone to plan his day to day travel.

Toward the end of his time in PAY Check, Wyatt attended a job fair where he met the Guest Services Manager at Zoo. He was asked to come in the following week for an interview. Staff met with Wyatt frequently during that week to provide interview training. Wyatt interviewed and was offered a job in guest services on the spot. The manager felt that Wyatt exuded characteristics that he wanted in his department. Part of Wyatt's job now is to ensure the safety of individuals on the carousel and to teach new staff members to do the same. Recently, Wyatt set a goal of becoming employee of the month. He achieved that goal the following month!

Wyatt feels that his job adds value and purpose to his life. He is now able to save money, budget, and set big goals for the future for where he wants to live and work. Since beginning work Wyatt has become an advocate. He is pushing for others with disabilities to have the opportunity to go to work and earn wages. In 2018, he was voted a be one of the 2018 "Storytellers" by Rooted in Rights where he speaks about for the importance of employment for people with disabilities. Wyatt has also become an active member of the LSU Human Development Center's Consumer Advisory Committee (CAC) where he helps ensure that HDC is focusing on its mission and goals. Finally, Wyatt "pays it forward" by visiting the current PAY Check students and encouraging them 
to make efforts to dig in and get the most of their experiences in the program.

\subsection{Gwen}

Gwen is a 19-year old young women with an IEP exceptionality of "mild mental disability." She also identified as "gifted and talented in visual arts." She was enrolled in self-contained classes and was on a "certificate of completion" graduation track.

Gwen had one of the biggest transformations in our program. In fact she won the biggest transformation award at the PAY Check graduation ceremony. Before beginning the PAY Check program, Gwen was often described as painfully shy and reserved. She came into the program with many fears and reservations. For example, Gwen was terrified of meeting new people or even having a conversation with someone she already knew. She feared interacting with people to the point she could not even order food by phone or in person. Even after mastering use of the public bus system, Gwen was afraid ride the bus alone. She feared eating in public spaces and completing simple tasks such as studying in the library alone. Asking for help frightened her. Gwen's biggest fear was being in a classroom that wasn't self-contained. She told staff she did not know how to act in a "regular classroom" and feared students would figure out she does not belong and judge her.

PAY Check staff worked with Gwen to equip her with the skills she needed to overcome her fears. To do that, most of Gwen's weekly goals focused on addressing her fears head on. She set weekly goals of getting to know her classmates and community training outings often involved ordering food around various restaurants in the city of New Orleans and using public transportation alone to get around. After some months went by Gwen began noticing a change in herself. During the paid apprenticeship at The University Medical Center, she worked in the Human Resource Department as a file clerk. One of her daily tasks was to maintain the files in the employee file room. For security reasons the room was locked. So everyday Gwen had to ask an employee for the key to the file room. For most people this step would take but a minute; but for Gwen it took 45 minutes to an hour due to the anxiety she experienced. We could have made it easy for her by asking for her own key but that wouldn't have helped her in the long run. Gwen took five semesters to finish the typically 3-semester PAY Check program. After her paid apprenticeship at the hospital ended she was employed as student worker in a childcare center. Today Gwen is working at a local YMCA as a child care aide. She's working 4-5 days a week and picking up shifts whenever possible. Gwen recently celebrated her 19th birthday. Staff were impressed when she called to inform them that she ordered pizza all by herself!

\section{Program outcomes}

Outcomes achieved by completers of the first cohort of PAY Check program youth are described below. Because PAY Check is an individualized program, the length of time it takes participants to complete the program varies. Outcomes reported here include only the eight of twelve youth who were enrolled in the first cohort of PAY Check program who completed the program by the end of the 2018 spring semester. Seven of the eight completers $(87.5 \%)$ were competitively employed in natural community settings. At the time of the writing of this article, six of them $(75 \%)$ had retained their employment. The types of jobs completers obtained include: Child Care assistant, store associate and security staff.

In Louisiana, students with an IEP may select and complete an approved career pathway as an alternative to the standard Carnegie Units required for a general education diploma and in so doing may earn a regular diploma without passing the high stakes exit exam. All but one of the cohort one PAY Check participant $(87.5 \%)$ who completed the program by the end of the 2018 spring semester obtained a high school diploma. It is noteworthy that many PAY Check participants attended "self-contained" classrooms for some or all of their school day prior to enrolling in the program. However, all but one of the completers (87.5\%) obtained a GPA of 3.0 or higher in the classes they took at the Community College.

PAY Check completers acquired knowledge and skills for a variety of activities that are requisite to full participation in the community, including but not limited to: use their cell phones to stay in touch with family and staff when they were in the community without direct supervision, look up information on search engines (e.g., Google), plan and use the public transportation system, including making transfers. Participants also learned to manage a debit card, and purchase items at the book store, cafeteria and various locations in the community. Participants learned to manage their time using a personal calendar to make and keep appointments with public support and 
service agencies, arrive for class and work on time, among other things. PAY Check completers set and monitored progress toward achieving personal goals, created a resume, performed personal job searches, arranged and completed job interviews.

\section{What we learned}

\subsection{How often we would have to defend our model of inclusion, particularly to educators}

It was surprising how often the program's model of independence and inclusion was questioned by secondary educators. The most common questions from the secondary educators included: Why are the students taking credit classes at the community college? Wouldn't it be better if they audited instead? Regular classes, not special education? But the work is going to be modified, right? You go to class with them, right? They will all go to classes together, right? They're going to learn to take the public bus by themselves? Wouldn't it be better to have them all use paratransit? They are going to have paying jobs in a hospital? And the jobs aren't in food service and janitorial? Couldn't they just volunteer? Without fail, each high school teacher who followed a student from the high school campus to the PAY Check program, stopped questioning our practices by the end of the first college semester at the student's personcentered planning meeting, if not before. They had become witness to students' success in navigating the community college campus, earning college credits, learning to independently utilize public transportation, and began to believe the same success could take place at the apprenticeship site.

\subsection{How supportive and collaborative the post-secondary instructors were with pay check students and staff}

The instructors at the community college were receptive to students in their classes who attended regularly and who demonstrated a desire to do their best work. This is not limited to the students in PAY Check, but to all students. At the beginning of each semester, PAY Check Transition Specialists introduced themselves to the instructors, provided information on the program, and assured the instructor they were committed to a partnership to the degree needed to support PAY Check students in their classes. Students who consistently attended classes and completed their assignments, did very well in their classes and earned above average grades. The instructors at the community college embraced the diverse student population on campus, evidenced by the culture in their classes and their openness to unique needs.

\subsection{Many obstacles faced by pay check students had nothing to do with their disabilities}

We mistakenly assumed the "real" obstacles PAY Check students would face daily would have everything to do with their disability labels and the challenges that can accompany those labels. Not so. Poverty, homelessness, and family issues were some of the real challenges. Other obstacles were frequently a result of their age, being glued to their smartphones or their earbuds, not sleeping enough, surviving on vending machine food, or losing bus passes. Early in their Pay Check journey, it became apparent that none of the students had ever been taught how to set goals, or knew how to set goals for themselves, make a plan and take all of the steps necessary to follow through to completion, or how to get or stay organized. Most of the participants had never had the freedom to make independent choices and decisions that were typically made for them. Following through on the day's schedule or initiating the communication if the plan needed to change were daily challenges unrelated to their disabilities.

\subsection{How much intervention the families need}

Families have a critically important role in the transition process. At a minimum, they must support their student to actively participate in community college, learn community living skills (banking, public transportation, etc.) and work-related skills, and ultimately support their student to reach the outcome of competitive employment in the community. The amount of time required by transition specialists to achieve some of these program components with families was certainly more than anticipated, especially since each student applied to participate and a family member was included in the interview process. As an example, each family member was told several times (and in writing) that one of the objectives participants was learn to use public transportation independently. Even so, when the time came to learn to use public transportation, several family members attempted to forbid it for their son or daughter. It seemed plausible they were acting based upon previous experiences 
where requirements or expectations were changed for their student after worries, fears, or concerns were made known. Certainly we accepted and appreciated their feedback and lifelong history and knowledge of their young adult, and certainly we made adjustments based on the unique needs of each student, but blanket exceptions were not made. Therefore, significant discussion and collaboration with the families was required to keep everyone working together, as comfortably as possible, to meet the expectations set for participants.

\subsection{New expectations: How challenging it would be to break through low expectations for and by students}

With college comes school work and with a job comes expectations and responsibilities. PAY Check transition specialists had appropriate expectations for the students. It was believed that if the task or assignment was broken down into manageable parts, students would be successful if they did their best work and had an appropriate level of support. In comparison to the expectations the students were accustomed to being held the new expectations were perceived to be high by some families, educators, rehab providers, and youth themselves.

Most of the students in PAY Check were not accustomed to having to complete school work daily, make their own transportation plans, deal appropriately with stress and frustration, manage their time, make independent decisions and budget their money. They did not think they could do those things or learn to become independent in those areas because they had been told, either directly or indirectly, that they would not be able. Initially, participants' expectations of themselves, which were derived from the low expectations others had for them, were a challenge. Transition specialists employed a variety of strategies to build up their confidence and provide encouragement to strive for success and to reinforce incremental steps that lead to success. In time, a shift in student self-confidence and self-determination was noticeable.

\subsection{Leaps and bounds: How much the students would grow in a short span of time}

It was remarkable to evidence the rapid growth in all of the Pay Check students within the first semester of the program. One student who had previously isolated himself, kept his head down, and interacted mostly with the cell phone in his hand became a student who could be seen talking, laughing and playing video games with other students in the community college student life center. Another participant who was so unsure of what he needed to do who would separately seek reassurance from each of the Transition Specialists became one who would determine his own plan and then perhaps check in with one transition specialist for confirmation. A young woman who would not speak to unfamiliar people began to do so independently when it was necessary to complete a task. A student who had no experience riding a bus or walking alone began to do both. You who had segregated high school educational experiences were successful in typical community college classes. Significant and notable changes within all occurred within the first semester of PAY Check, prior to the apprenticeships, and each continued to sharpen their newly acquired skills and develop new ones throughout their work-based learning experiences.

\section{Recommendations}

Most pre-transition age youth with receive the vast majority of their instruction, supports and services within the bounded settings and predictable, pre-set, targeted, yet limited, activities that comprise their school-based program. As youth with disabilities approach transition-age it is imperative that they be exposed to, and become competent in, negotiating dynamic authentic community settings and activities.

Youth with disabilities, especially those with intellectual disabilities, often have difficulties generalizing their abilities to recognize and respond appropriately to the infinite variety of antecedent cues that signal the need or opportunity to engage, or not engage, in particular behaviors in different settings, people, materials and/or other environmental constraints and distractors (c.f., Wilcox \& Bellamy, 1982). The focus of transition programs for youth with disabilities must include strategies to facilitate acquisition of and practice using, knowledge and skills relevant to participation in the community. Transition programs for youth disabilities must also equip participants to recognize the cues and to use knowledge and skills under the appropriate circumstances. For these reasons, we recommend that transition programs for youth with disabilities include supports and services designed to promote participants' ability to generalize their capacity to recognize and respond appropriately to antecedent cues in a 
variety of authentic community environments (e.g., guided practice recognizing generalizable cues with systematic withdrawal of staff support). This is particularly important for students with intellectual disabilities.

Other more difficult to identify and document influences on the ability of youth with disabilities to participate fully in the community may be subsumed under the heading of "feelings". Full participation in the community requires a healthy sense of self and purpose. Unfortunately, the lived experience of many children and youth with disabilities includes inadvertent "learned helplessness" (Mikulincer, 1994; Seligman, 1975) and lacks instruction and opportunities to practice self-determination and other agency-building behaviors (Deci, 1985). We recommend that transition programs for youth with disabilities target development and/or strengthening of an array of affective and interpersonal skills and traits (e.g., self-confidence, self-determination, pride, etc.). Learning such compensatory strategies will allow them to recognize and modulate their internal states (i.e., feelings) to overcome obstacles and achieve goals that result in greater participation in the community.

As described in detail in the literature, we recommend that curricula for transition programs for youth with disabilities be based on key experiences, knowledge and skills demonstrated in the literature (c.f., National Technical Assistance Center for Transition (NTACT)). Recommendations for program components from NTACT and other sources include, but are not limited to: career awareness, community experience, high school diploma attainment and/or stackable work-based credentials, interagency collaboration, parent/family involvement, self-advocacy, -determination, -care, independent living, social, and transportation skills.

In addition to the standard components recommended for transition programs for youth with disabilities cited above, we recommend that transition age youth (i.e., 18-14 years) with disabilities spend the majority, if not all, of their "instructional" time away from their high school in settings that are typical for their non-disabled age-peers. Usually this will involve post-secondary education (e.g., community college, vocational-technical school, college or university) and community employment. The employment component of the program should include wages at, or above minimum wage, support in identifying career interests, job searching, obtaining and maintaining a job (resume development, on-line and in person applications, interviewing, etc.). Other 21 st century curricular targets and activities should include, but are not limited to, topics such as: banking, public transportation, use of smart phone and computer/tablet, to name a few.

\section{Conflict of interest}

The authors declare that they have no conflict of interest.

\section{References}

Deci, E. L., \& Ryan, R. M. (1985). Intrinsic motivation and selfdetermination in human behavior. New York, NY: Plenum.

Horner, R. H., Sprague, J., \& Wilcox, B. (1982). General case programming for community activities. In B. Wilcox \& G. T. Bellamy (Eds.), Design of high school programs for severely handicapped students. Baltimore, MD: Paul H. Brookes Publishing Co.

Individuals with Disabilities Education Act, 20 U.S.C. $\S 1400$ (2013).

Migliore, A., Butterworth, J. \& Hart, D. (2009) Postsecondary Education and Employment Outcomes for Youth with Intellectual Disabilities. Think College! Fast Facts No.1.

Mikulincer, M. (1994). Human learned helplessness: A coping perspective. Plenum Series in Social/Clinical Psychology. New York, NY: Plenum. DOI: 10.1007/978-1-4899-0936-7

Seligman, M. E. P. (1975). Helplessness: On depression, development, and death. San Francisco, CA: W. H. Freeman. 